\title{
Hydrodynamic Performance Analysis on Different Airfoils of Straight Blade H Type of Vertical Axis Tidal Current Energy Turbine
}

\author{
Kan Kan ${ }^{1}$, Yuan Zheng ${ }^{2,3}$, Xiaoling Liang ${ }^{4}$, Shifeng Fu' ${ }^{1}$, Zhongwei $\mathrm{He}^{1}$ and Bin Sun ${ }^{1}$ \\ ${ }^{1}$ College of Water Conservancy and Hydropower Engineering, Hohai University, Nanjing, 210098, P.R. China \\ ${ }^{2}$ National Engineering Research Center of Water Resources Efficient Utilization and Engineering Safety, Nanjing, 210098, P.R. China \\ ${ }^{3}$ College of Energy and Electrical Engineering, Hohai University, Nanjing, 210098, P.R. China \\ ${ }^{4}$ College of Mechanical Engineering, Hohai University Wentian College, Maanshan, 243031, P.R.China
}

\begin{abstract}
Airfoil is a key factor that influences the hydrodynamic performance of vertical axis tidal current energy turbine. In order to explore the influences from the runner's blade airfoil towards its hydrodynamic performance, three-dimensional unsteady flow numerical simulation on four airfoils of straight blade $\mathrm{H}$ type of tidal current energy turbines was carried out, under the precondition of same turbine compactness. Through investigating the influences from the four different airfoils of $\mathrm{H}$ blade towards the runner in terms of its dynamic torque feature and hydropower utilization coefficient, this research has analyzed the hydrodynamic performance of the tidal current energy turbine. As the research result indicates, the maximum dynamic torque value of the single-blade turbine with NACA0015 airfoil is significantly higher than that of the other three airfoils; while the maximum value of the overall runner torque is determined by the operating conditions such as different stream speed etc. As a whole, hydropower utilization coefficient of the turbine with asymmetric airfoil NACA4415 is better than that of the other three airfoils. This research has provided references for the design and airfoil selection for the new type of tidal current energy turbine.
\end{abstract}

\section{Introduction}

With the constant consumption of the non-renewable energy resources like coal and petroleum, environmental pollution issue is increasingly severe and the contradiction between energy supply and demand is becoming more and more intensified. Under such background, the tidal current, as a kind of abundant, renewable and clean energy, has obtained substantial attention [1]. Tidal current energy is rather common in China with a total production as high as 140 million KW. Under contemporary times when energy crisis and maritime rights issue are becoming more and more prominent, reinforcing the development and utilization efforts in tidal current energy has become beneficial to the world's rapid economic development pace.

In recent years, vertical axis tidal current energy turbine has obtained rapid development across the world. In 2002, Italian (PdA) company has successfully launched the floating vertical axis straight blade varying roar turbine in the Mexico strait [2]. U.S. GCK Technology Company has developed the vertical axis tidal current energy turbine (GHT). By adopting spiral blades with certain rotation degree, the vertical axis turbine will operate in a steadier mode and is much easier to launch compared to the one using straight blade [3]. In 2000-2011, Korea applied the American technology and established the tidal power station at the downstream of the Myeongryang Strait Bridge of Jindo County. With two $500 \mathrm{KW}$ vertical axis turbines installed, the station is supported by steel jackets with transformer and control room located on the bank. After the resource exploration and site selection at the first phase as well as site construction and pilot run at the second phase, this power station has been officially put into operation in 2011 [4]. In addition, Ocean University of China has developed a floating vertical axis tidal current turbine power generating set [5]. By adopting soft blade, which is similar to the sailing wing, this set can fully utilize the elevating force and resistance effects. In 2008, this vertical axis tidal turbine power generation set has been successfully tested in Zhaitang Island water area of Jiaonan City of Qingdao. In August 2012, "Marine Energy I", which is developed by renewable energy research institute of Harbin Engineering University, has been accepted with total installed capacity of 300KW [6]. Vertical axis water turbine is featured by simple structured blade, no convection device and lower maintenance costs [7]. Most current studies concentrate on one single aspect without covering the comprehensive impacting factors that influence the hydrodynamic performance of the straight blade $\mathrm{H}$ vertical axis water turbine. At the present study, through combining the blade element theory and the three-dimensional numerical simulation method, analysis on the influences from different airfoils and stream speeds towards the 
runner's dynamic torque feature and hydrodynamic utilization was accomplished. Based on the analysis, the optimal blade tip speed ratio providing essential references to the design and airfoil selection for the tidal current energy water turbine.

\section{Physical model}

\subsection{Geometric modeling}

In order to analyze the influences from different airfoils towards the hydrodynamic performances of the vertical axis tidal current energy water turbine, this paper has first ensured the precondition of same turbine compactness. And then by employing Gambit software, it has established the three-dimensional model for the turbine runner under different types of airfoils. The airfoils used in this research include NACA4415, NACA0015, NASANLF0416 and S1210 [7], which are shown in Fig. 1.

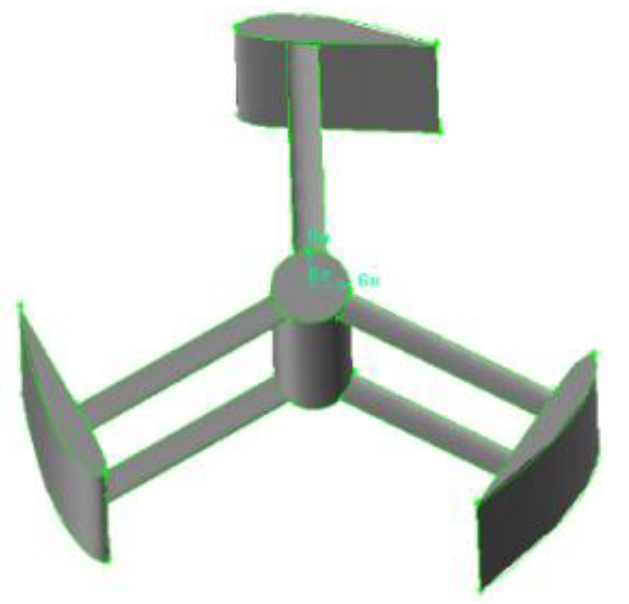

(a) NACA4415

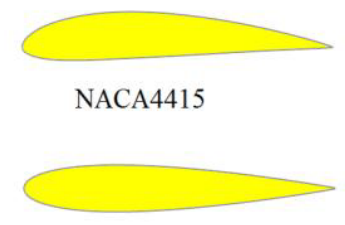

NACA0015

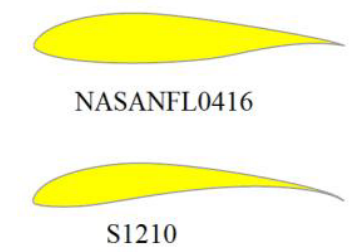

(b) Four types of airfoils

Figure 1. Turbine's runner model under different airfoils

Compactness definition for vertical axis $\mathrm{H}$ type of blade:

$$
\sigma=\frac{z c}{\pi d}
$$

Compactness of the turbine is normally set as $0.15 \sim 0.5$. This paper has set the value as 0.35 with $\mathrm{z}$ as the blade number, $\mathrm{c}$ as the chord and $\mathrm{d}$ as the runner's diameter.

\subsection{Parameters of the turbine mode}

Basic parameters for straight $\mathrm{H}$ type of tidal current energy water turbine are shown in Table 1.

Table 1. Basic parameters for runner of vertical axis tidal energy water turbine

\begin{tabular}{|c|c|}
\hline Parameter Name & Straight blade \\
\hline $\begin{array}{c}\text { External diameter of the } \\
\text { turbine } D_{1}(m)\end{array}$ & 3.5 \\
\hline $\begin{array}{c}\text { Hub diameter of the } \\
\text { turbine } D_{2}(m)\end{array}$ & 0.5 \\
\hline Blade height $h(m)$ & 4 \\
\hline $\begin{array}{c}\text { Incidence angle of the } \\
\text { blade } \varphi\left({ }^{\circ}\right)\end{array}$ & 3 \\
\hline $\begin{array}{c}\text { Number of blades } Z \\
\text { Airfoil of the support } \\
\text { frame }\end{array}$ & NACA0015 \\
\hline $\begin{array}{c}\text { Chord of the main airfoil } \\
C_{1}(m)\end{array}$ & 1.28 \\
\hline \begin{tabular}{c} 
Parameter Name \\
\hline
\end{tabular} & Straight blade \\
\hline
\end{tabular}

\section{Three-dimensional Simulation Computation}

\subsection{CFD computation method}

During the operation of vertical axis turbine, the external flowing medium water is incompressible viscous fluid and the blade surface is mainly subject to gravity, water pressure and centrifugal force. Thus, this research adopts the Navie-Stokes equations based on Reynolds averaged equations and Spalart-Allmaras turbulence model [8] in performing the CFD numerical simulation on the flowing field at the runner area of vertical axis turbine. The equation is:

$$
\frac{\partial u_{i}}{\partial x_{i}}=0
$$

N-S equation:

$$
\rho \frac{\partial}{\partial t}\left(u_{i}\right)+\rho u_{j} \frac{\partial}{\partial x_{j}}\left(u_{i}\right)=\rho F_{i}-\frac{\partial p}{\partial x_{i}}+\mu \frac{\partial^{2} u_{i}}{\partial x_{j} \partial x_{j}}
$$

Wherein, $\rho$ is the fluid density; $u$ is the fluid velocity vector; $F$ is the mass force; $p$ is the pressure; $\mu$ is the eddy viscosity; above computation has adopted the Second Order Upwind format so as to improve the computing accuracy. Besides, it has utilized non-steady implicit solution with time step as $0.01 \mathrm{~s}$. Moreover, it has employed SIMPLEC computation method in achieving the coupling between pressure and speed.

\subsection{Boundary condition}

Boundary condition at the inflow entrance is set as the velocity inlet; the cylinder surface where the turbine 
locates is set as the glide plane. Under the condition where pressure is resumed to the inflow static pressure, set the boundary condition at the cross section of the stream effluent as the average static pressure outlet, for incompressible fluid, the surface of the runner and support blade as well as the flow passage is set as no slip boundary condition.

\subsection{Computational domain and meshing}

Actually, tidal current energy turbine is operating in a very large area under the sea. According to the basic parameters of the turbine model, this paper has established a rectangular area as the flowing area around the vertical axis turbine as well as the computational domain. Select the central point under the bottom of turbine's rotation axis as the origin of coordinates with flow direction along the positive direction of $\mathrm{x}$ and principle axis direction as $\mathrm{z}$. Then the computational domain size is: $X_{\max }$ is $14 \mathrm{~m}, X_{\min }$ is $-7 \mathrm{~m} ; Y_{\max }$ is $3.5 \mathrm{~m}$ and $Y_{\min }$ is $-3.5 \mathrm{~m} ; Z_{\max }$ is $4.25 \mathrm{~m}$ and $Z_{\min }-0.25 \mathrm{~m}$. And the overall computational domain size is: $21 m \times 7 m \times 4.5 m$. To ensure the accuracy of the simulation computation, this research further classifies the computational domain into two parts. Part one is defined as a cylinder area with radius as $2 \mathrm{~m}$ and height as $4.5 \mathrm{~m}$, which closely encircles the vertical axis turbine. Moreover, the meshes in this area has refined and the cylinder surface was defined as the sliding boundary. And the rest part of the rectangular area is defined as the part two. Furthermore, ANSYS ICEM Software mesh on above two areas. And given the runner is normally coated with irregular complex curved surfaces, this research has adopted tetrahedral unstructured mesh in segmentation. At last, there are around 2.35 million meshes in the rotating area and 0.9 million meshes in the external flowing field.

\section{Computation result analysis}

\subsection{Influence from the airfoil towards runner's dynamic torque feature}

As shown by Fig. 2, under the operating condition when the velocity inlet for four airfoils of turbines is $\mathrm{v}=1.5 \mathrm{~m} / \mathrm{s}$ and $\mathrm{v}=2 \mathrm{~m} / \mathrm{s}$ respectively and the rotating speed is $13.38 \mathrm{r} / \mathrm{min}$, the torque change curve graph for single runner blade is presented as below. Indicating that when the velocity inlet is $\mathrm{v}=1.5 \mathrm{~m} / \mathrm{s}$ or $\mathrm{v}=2 \mathrm{~m} / \mathrm{s}$, torque change curve is basically the same for different airfoils of single blades. And with the rising of speed, maximum torque value for turbine blade at the same airfoil is improving; whereas the minimum value is decreasing. Within one cycle, single blade torque fluctuation of airfoil S1210 is significantly large but the torque value generated is relatively smaller.
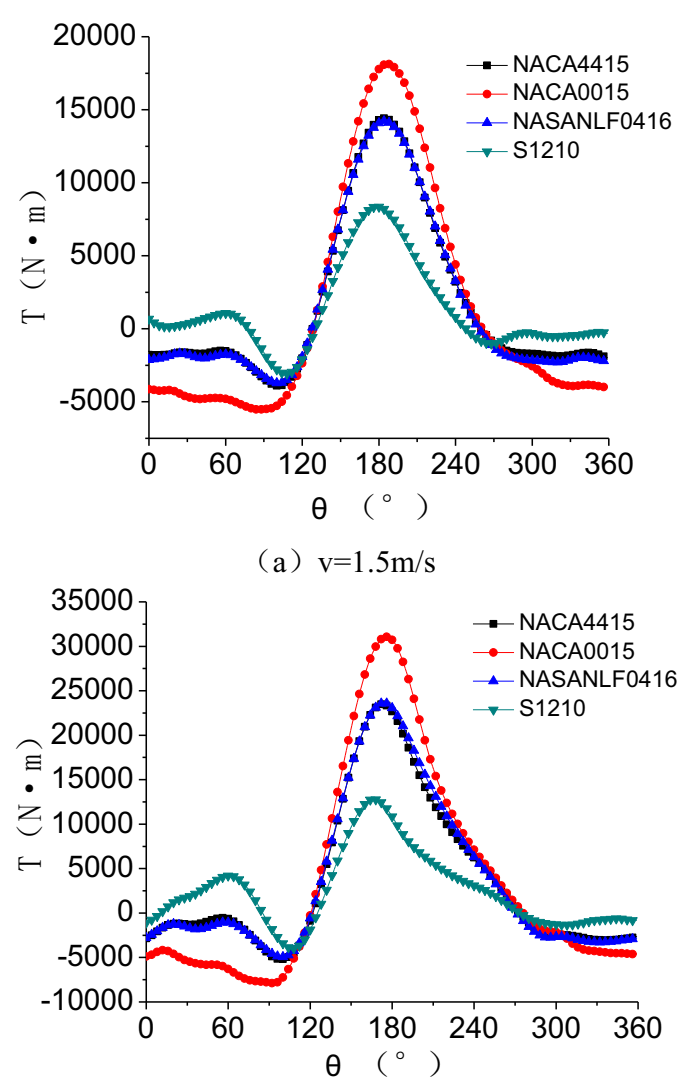

(b) $\mathrm{v}=2.0 \mathrm{~m} / \mathrm{s}$

Figure 2. Comparative graph for single blade under different airfoils

Through comparing the torque value of the single blade under different airfoils in Fig. 2, it's detected: maximum torque value of NACA0015 airfoil is significantly higher than that of the other three airfoils and its minimum value is smaller than the other three airfoils as well; torque value generated by NACA4415and NASANLF0416 is close to each other; when the phase degree $\theta$ is $120^{\circ} \sim 270^{\circ}$, torque value of all airfoils will first increase and then decrease with all of them as positive and the blades doing positive work; whereas, when the phase degree is beyond above range, torque value of single blade for S1210 airfoil is obviously higher than that of the other airfoils; meanwhile, only the blade for this type of airfoil alone is obtaining positive value within a small range, and it's majorly doing negative work within this area.

As shown from Fig. 3: the torque change curve for the overall runner of different airfoils is composed by the torques of the straight blades from three runners. Under the conditions when the rotation speed is $13.38 \mathrm{r} / \mathrm{min}$ and velocity inlet is $\mathrm{v}=1.5 \mathrm{~m} / \mathrm{s}$ or $\mathrm{v}=2.0 \mathrm{~m} / \mathrm{s}$, overall torque value for runner with airfoil S1210 is the lowest. But with different operating conditions, the maximum overall torque value is different. When the inlet velocity is $\mathrm{v}=1.5 \mathrm{~m} / \mathrm{s}$, overall torque for NACA4415 is the largest, followed by NACA0015, NASANLF0416 and S1210 at last. And when $v=2.0 \mathrm{~m} / \mathrm{s}$, overall torque value for runner with airfoil NACA0015 is much larger than that of the other three airfoils. NACA4415 and NASANLF0416 are close to each other with the former slightly larger than the latter, but S1210 falls far behind from above three airfoils. 
In general, under different operating conditions, the optimal airfoil with the largest torque value will also alter.

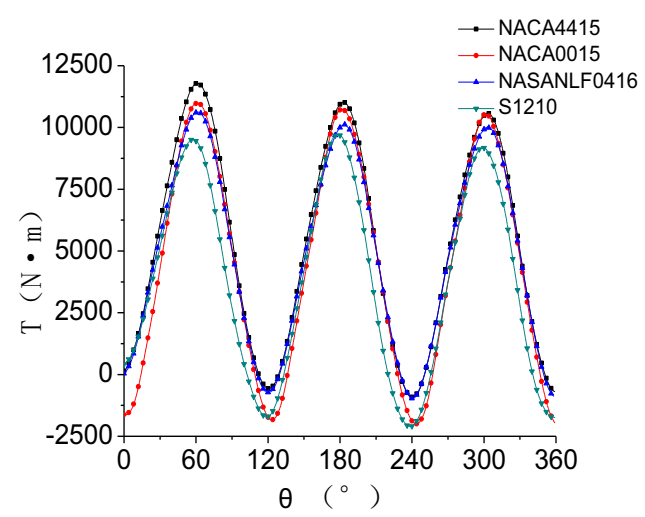

(a) $\mathrm{v}=1.5 \mathrm{~m} / \mathrm{s}$

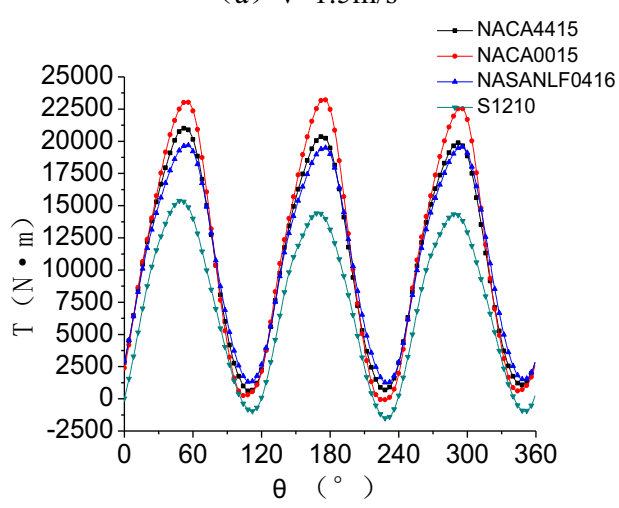

(b) $\mathrm{v}=2.0 \mathrm{~m} / \mathrm{s}$

Figure 3. Comparison graph for turbine runner's torque under different airfoils

\subsection{Influence from airfoil to runner's hydropower utilization coefficient}

Through utilizing FLUENT Software, this search has applied simulation computation on the vertical axis tidal current energy turbine model. Given it is non-steady numerical simulation, when the iteration convergence turns steady, runner's torque value is manifested as a flat curve with regular fluctuations. And by integrating on the torque curve with certain period of time, average torque $\mathrm{T}$ is computed and then via computation formula (4):

$$
C_{P}=\frac{P}{\frac{1}{2} \rho v^{3} A}=\frac{T \omega}{\frac{1}{2} \rho v^{3} A}
$$

Wherein, $P$ is the power actually obtained by the turbine's runner with the unit as $W ; \rho$ is the fluid density with the unit as $\mathrm{kg} / \mathrm{m}^{3} ; v_{\text {is the flowing speed }}$ with the unit as $m / s ; A$ is the swept area of the runner with the unit as $m^{2} ; T$ is the torque with the unit as $N \cdot m ; \omega$ is the rotating speed of the runner with the unit as $r / \min$

The hydropower utilization coefficient, which is also known as the efficiency, can be derived from above formula. Efficiency output comparison is shown as Table 2.

Table 2. Efficiency output comparison

\begin{tabular}{|c|c|c|c|c|c|c|}
\hline \multirow{2}{*}{$\begin{array}{c}\omega \\
(\mathrm{r} / \mathrm{min})\end{array}$} & \multirow{2}{*}{$\begin{array}{c}v \\
(\mathrm{~m} / \mathrm{s})\end{array}$} & \multirow[t]{2}{*}{$\lambda$} & \multicolumn{4}{|c|}{$\mathrm{Cp} / \%$} \\
\hline & & & $\begin{array}{c}\text { NACA } \\
4415\end{array}$ & $\begin{array}{c}\text { NACA } \\
0015\end{array}$ & $\begin{array}{c}\text { NASANLF } \\
0416\end{array}$ & $\mathrm{~S} 1210$ \\
\hline 13.38 & 1.00 & 2.45 & -0.01 & -10.8 & -3.72 & 8.30 \\
\hline 13.38 & 1.3 & 1.81 & 28.46 & 20.61 & 26.30 & 21.68 \\
\hline 13.38 & 1.50 & 1.63 & 31.21 & 26.44 & 28.89 & 21.25 \\
\hline 13.38 & 2.00 & 1.23 & 26.7 & 28.31 & 26.77 & 17.79 \\
\hline 13.38 & 2.50 & 0.98 & 21.2 & 23.49 & 21.74 & 13.65 \\
\hline 13.38 & 3.00 & 0.82 & 15.55 & 17.53 & 15.59 & 10.05 \\
\hline
\end{tabular}

According to the statistics from the table, efficiency change curve per blade tip speed is presented as below Fig. 4.

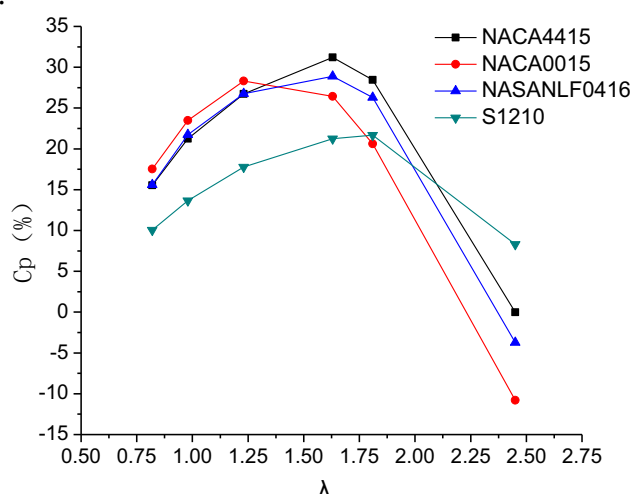

Figure 4. Efficiency curve comparison graph for turbines under different airfoils

Efficiency curve comparison graph for turbines under different airfoils is shown as Fig. 4. Through comparing the efficiency of the runners under the four airfoils, it's indicated: 1. With different airfoils, the highest efficiency of the vertical axis tidal current energy turbine is matched with different optimal operating conditions and different optimal blade tip speed ratio. To be specific, the optimal blade tip speed ratio for airfoil NACA0015 is 1.23 , that for NACA4415 and NASANLF0416 is 1.64 and that for $\mathrm{S} 1210$ is 1.81 . Generally speaking, blade tip ratio $\lambda$ at the high efficiency area for all airfoils is within $1 \sim 2.2$. When the blade tip ratio $\lambda$ is smaller than 1.3 , the vertical axis turbine efficiency for airfoil NACA0015 is higher than that of the other three airfoils; efficiency of NACA4415and NASANLF0416 is close to each other and S1210 ranks last. When the blade tip ratio $\lambda$ falls 1.3 1.8, efficiency of airfoil NACA4415 ranks the top, followed by NASANLF0416, NACA0015 and S1210. 3. When the blade tip ratio $\lambda$ is larger than 2.1 , turbine efficiency of all airfoils are relatively lower. And at this point, hydropower utilization coefficient of airfoil S1210 is higher than that of the other three airfoils, reaching as high as $31.21 \%$ and obtaining a better stability. At last, as indicated from Fig. 4, when the blade tip speed ratio $\lambda$ is relatively larger, such as larger than 2.35 , then the hydropower utilization coefficient of vertical axis tidal current energy turbine is very low with that of airfoil NACA4415, NACA0015 and NASANLF0416 even turning to negative value. Under such condition, the incoming fluid will turn around the runner's blade and generate larger resistance than elevating force. Hence, the 
tidal current energy turbine will not do any work and can't operate.

\section{Conclusion}

Through utilizing the three-dimensional numerical simulation method and analyzing the hydrodynamic performance of the straight blade $\mathrm{H}$ type of tidal energy current turbine under four different airfoils of runner blades, the conclusion is derived as below:

a. as far as the singe blade of tidal current energy turbine is concerned, torque value of airfoil NACA0015 is significantly higher than that of the other three airfoils; torque generated by NACA4415 and NASANLF0416 is extremely close to each other and the torque value of single blade under airfoil S1210 is relatively lower as a whole. Besides, when the phase degree $\theta$ is within the range of $120^{\circ} \sim 270^{\circ}$, then the torque will first increase and then decrease and do positive work; whereas, for the other phase degree, it will mainly do a negative work. As for the overall runner, with different operating conditions, airfoil for the optimal runner which obtains the maximum torque value will also vary.

b. the optimal blade tip speed ratio for airfoil NACA0015 is 1.23 and that for NACA4415 and NASANLF0416 is both 1.63, while that for S1210 is 1.81 . Besides, the blade tip ratio $\lambda$ at the high efficiency area for all airfoils is within 1-2. And as a whole, hydropower utilization efficiency of asymmetric airfoil NACA4415 is better than that of the other three airfoils, reaching as high as $31.21 \%$ with better stability. This is followed by airfoil NACA0015 and NASANLF0416 with airfoil S1210 ranking the last.

\section{Acknowledgments}

The work is financially supported by the State Key Program of National Natural Science of China:51579080, the Fundamental Research Funds for the Central
Universities (No. 2015B33814) and Jiangsu Provincial Graduate Student Innovation Project (Project No.: CXZZ13_0257).

\section{References}

1. T. J. Chu, Development and utilization of ocean energy resources, Beijing: Chemical Industry, (2015)

2. G. Calcagno, F. Salvatore, L. Greco, et al. An experimental investigation and a theoretical and computational methodology to study an innovative technology for marine current exploitation: the Kobold turbine, Bollettino della Comunità Scientifica in Australasia, (2006)

3. Verdant Power L L C. GCK Technology, Inc. Amesbury Tidal Energy Project: Integration of the Gorlov Helical Turbine into Optimized Hardware/ Software System Platform, MTC Final Report, (2005)

4. S. J. Wang, Study on hydrodynamic performances of a tidal current energy conversion device with flexible blade turbine, (2009)

5. L Zhang, Z. C. Li, X. W. Liang, et al, The status of research and application of vertical axis tidal turbine, Applied Energy Technology, 9 ,1 (2011)

6. Z. C. Li, K. Sun, F. M. Jing, et al, Study on the blade preset pitch of a fixed pitch vertical axis tidal turbine, Journal of Harbin Engineering University, 32, $7(2011)$

7. Y. W. Li, Marine energy exploitation, Beijing: Ocean, (2008)

8. H. K. Versteeg, W. Malalasekera, An Introduction to Computational Fluid Dynamics: The Finite Volume Method.New York: Wiley, (1995)

9. Falconer R A. Ahmadian R, Assessment of array shape of tidal stream turbines on hydroenvironmental impacts and power output, Renewable Energy, 44: 318-327, (2012) 